\title{
Direct Conversion of Aromatic Aldehydes into Benzamides via Oxidation with Potassium Permanganate in Liquid Ammonia
}

\author{
Damian Antoniak \\ Arkadiusz Sakowicz \\ Rafał Loska \\ Mieczysław Mąkosza*
}

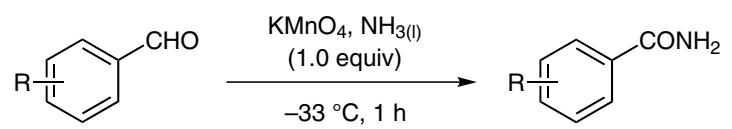

Institute of Organic Chemistry, Polish Academy of Sciences, Kasprzaka 44/52, 01-224 Warsaw 42, Poland icho-s@icho.edu.pl

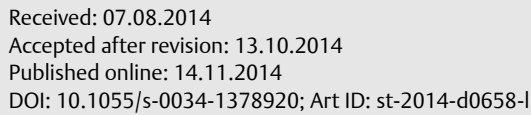

Abstract Oxidation of aromatic aldehydes by $\mathrm{KMnO}_{4}$ in liquid ammonia gives amides directly. The reaction proceeds satisfactorily when the aldehydes are activated by electron-withdrawing substituents on the ring.

Key words aldehydes, amides, aminals, oxidation, liquid ammonia

The amide functionality is ubiquitous, and amides are also versatile educts in organic synthesis; thus there is continuing interest in their synthesis. ${ }^{1}$ Of particular interest are possibilities of direct conversion of simple substrates into amides which bypass conventional routes, such as reaction of activated carboxylic acids with ammonia or partial hydrolysis of nitriles. In recent years there have been many reports on direct conversion of aromatic aldehydes and benzylic alcohols into amides via oxidative reactions in the presence of an ammonia source. Thus treatment of aromatic aldehydes with aqueous ammonia and iodine and hydrogen peroxide gave amides in excellent yields. ${ }^{2}$ Other ways to afford this transformation consist of conversion of aldehydes and primary alcohols into amides via reaction with ammonium carbonate and tert-butyl hydroperoxide with $\mathrm{Et}_{4} \mathrm{~N}^{+} \mathrm{I}^{-}$catalyst. ${ }^{3}$ Oxidative conversion of aldehydes and alcohols into amides via reaction with oxygen and various ammonia sources catalyzed by transition metals is described in a few papers. ${ }^{4}$ New examples of oxidative amidation of toluenes and styrenes ${ }^{5}$ and oxidative acylation with aldehydes ${ }^{6}$ have been reported recently.

Amongst a plethora of solvents used in organic synthesis and industry, liquid ammonia is of great interest because of its unique properties. Owing to its basicity and hydrogen-bond-accepting ability, liquid ammonia solvates efficiently inorganic cations such as $\mathrm{Li}^{+}, \mathrm{Na}^{+}, \mathrm{K}^{+}$; whereas, in spite of its formal protic character, it does not efficiently solvate anions. ${ }^{7}$ As a consequence it behaves as a dipolar aprotic solvent, dissolving inorganic salts and sodium or potassium salts of organic anions: alkoxides, enolates, and carbanions. ${ }^{7}$ Moreover, in liquid ammonia solution, anions of these salts exhibit high nucleophilic activity; thus it is the solvent of choice for many reactions involving carbanions ${ }^{8}$ and for industrial organic synthesis. ${ }^{9}$ Additionally, it is inexpensive, easy to handle under anhydrous conditions, and easy to remove and recover. Although ammonia can be oxidized and its oxidation to nitric acid is a major industrial process, liquid ammonia is resistant to common oxidants and forms stable solutions of potassium permanganate even at room temperature under pressure. ${ }^{10} \mathrm{~A} \mathrm{KMnO}_{4}$ solution in liquid ammonia has been efficiently applied to oxidation of $\sigma^{\mathrm{H}}$ adducts of carbanions and other nucleophiles to nitroarenes. ${ }^{11}$

Ammonia is also a moderately active nucleophile capable of forming $\sigma^{\mathrm{H}}$ adducts with highly electrophilic arenes, particularly azines, and so a solution of $\mathrm{KMnO}_{4}$ in liquid ammonia is an efficient agent for oxidative amination of such arenes. ${ }^{10}$ We therefore predicted that treatment of an aldehyde with such a solution should result in addition of ammonia to the carbonyl group followed by oxidation of the adduct to form an amide. Indeed, when solid $\mathrm{KMnO}_{4}$ was added to a solution of benzaldehyde in liquid ammonia the characteristic color of the solution slowly turned dark brown and, after evaporation of ammonia, the residue contained benzamide. After experimentation a convenient procedure was found in which the aldehyde was dissolved in liquid ammonia and, after stirring for one hour, $\mathrm{KMnO}_{4}(1.0$ or 1.5 equiv) was added and the mixture stirred for another hour. Excess permanganate was quenched with $\mathrm{Na}_{2} \mathrm{SO}_{3}(3$ equiv), the ammonia was evaporated, the residue treated with $6 \mathrm{M}$ hydrochloric acid, and the product extracted with ethyl acetate or filtered, washed with aqueous $\mathrm{NaHCO}_{3}$, and the product recrystallized. The results of these experiments are presented in Table $1 .{ }^{12}$

Aldehydes containing a halide or electron-withdrawing substituents gave the corresponding amides in good yields (Table 1, entries 2-8). The yields for nitrobenzaldehydes are somewhat lower due to side reactions and partial decomposition. Benzaldehyde and 1-naphthylcarboxyaldehyde gave the corresponding amides in moderate yield, together with small amounts of carboxylic acids. A careful analysis of the mass balance for the reaction of 4-cyanobenzalde- 
Table 1 Direct Oxidation of Aromatic Aldehydes to Amides

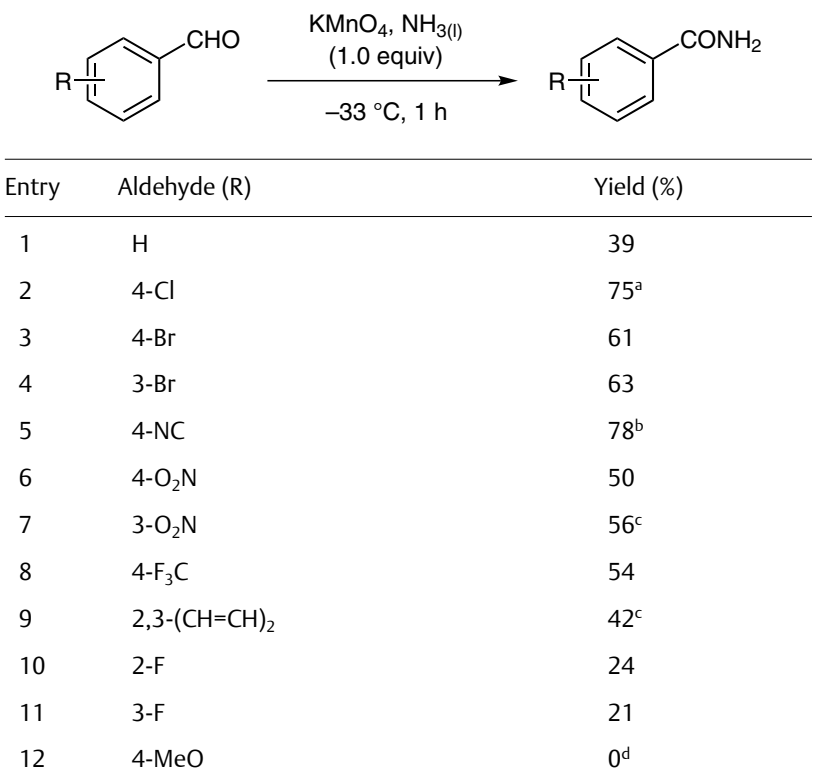

a Yield of carboxylic acid: $15 \%$.

${ }^{b}$ Yield of carboxylic acid: $20 \%$.

'Conditions: 1.5 equiv $\mathrm{KMnO}_{4}$.

${ }^{d}$ Yield of carboxylic acid: $85 \%$.

hyde showed that, even in this case, side formation of the carboxylic acid occurred. Its sodium salt was isolated in $20 \%$ yield, together with a high yield of the expected 4-cyanobenzamide (78\%). Similarly, 4-chlorobenzaldehyde gave a $75 \%$ yield of the amide and about $15 \%$ of the acid.

Aldehydes which are less prone to undergo nucleophilic addition to the carbonyl group, such as anisaldehyde (Table 1 , entry 11), ortho-substituted aldehydes (2,3-dichlorobenzaldehyde, 9-anthracenecarboxaldehyde), or aliphatic aldehydes (n-octanal), form carboxylic acids exclusively. 2Fluorobenzaldehyde is a borderline case as it gave a nearly equimolar mixture of 2 -fluorobenzamide and 2-fluorobenzoic acid, together with some unreacted aldehyde.

All benzamides obtained in the reactions summarized in Table 1 are known compounds and their identity and purity was confirmed by ${ }^{1} \mathrm{H}$ NMR, ${ }^{13} \mathrm{C}$ NMR, IR spectroscopy and comparison of melting points with literature data.

Oxidation of aldehydes with aqueous solutions of $\mathrm{KMnO}_{4}$ at various $\mathrm{pH}$ values has been the subject of thorough mechanistic studies. ${ }^{13}$ However, the mechanistic conclusions from these studies cannot be extended to the oxidation in liquid ammonia. It appears that conversion of aldehydes into amides in liquid ammonia proceeds via initial addition of ammonia to the carbonyl group. This supposition is supported by the observed effects of substituents in the aromatic rings on the reaction. Oxidation of the hypothetical intermediates - aminals - could proceed via abstraction of hydride anions analogously to hypothetical pathways of oxidation of $\sigma^{\mathrm{H}}$ adducts in oxidative nucleophilic substitution of hydrogen in arenes. ${ }^{14}$ On the other hand, when the dimethyl acetal of 4-bromobenzaldehyde was subjected to the reaction conditions, after acidic workup only 4-bromobenzaldehyde was obtained. This result could be explained by much faster oxidation of the aminal than the acetal function by $\mathrm{KMnO}_{4}$, or by assuming that the intermediate leading to an amide is an imine rather than an aminal.

In conclusion, we have described a simple and practical synthetic procedure by which aromatic aldehydes can be directly converted into benzamides. The scope of the reaction is somewhat limited by the concurrent formation of carboxylic acids, but these side products can be readily removed from the desired amides by simple washing with aqueous base.

\section{Supporting Information}

Supporting information for this article is available online at http://dx.doi.org/10.1055/s-0034-1378920.

\section{References and Notes}

(1) (a) Allen, C. L.; Wolliams, M. J. Chem. Soc. Rev. 2011, 40, 3405. (b) Valeur, E.; Bradley, M. Chem. Soc. Rev. 2009, 38, 606. (c) Humpwey, J. M.; Chamberin, A. R. Chem. Rev. 1997, 97, 2243.

(2) Shie, J.-J.; Fang, J.-M. J. Org. Chem. 2003, 68, 1158.

(3) Wang, G.; Yu, Q.-Y.; Chen, S.-Y.; Yu, X.-Q. Org. Biomol. Chem. 2014, 12, 414.

(4) Nie, R.; Shi, J.; Xia, S.; Shen, L.; Chen, P.; Hou, Z.; Xiao, F.-S. J. Mater. Chem. 2014, 22, 18115; and references cited therein.

(5) (a) Wang, Y.; Yamaguchi, K.; Mizuno, N. Angew. Chem. Int. Ed. 2012, 51, 7250. (b) Vanjari, R.; Guntreddi, T.; Nand Singh, K. Org. Lett. 2013, 15, 4908. (c) Sharif, M.; Gong, J.-L.; Langer, P.; Beller, M.; Wu, X.-F. Chem. Commun. 2014, 50, 4747.

(6) (a) Ekone-Kovi, K.; Wolf, C. Org. Synth. 2010, 87, 1. (b) GiguèreBisson, M.; Yoo, W.-J.; Li, C.-J. Org. Synth. 2011, 88, 14. (c) Möhlmann, L.; Ludwig, S.; Blechert, S. Beilstein J. Org. Chem. 2013, 9, 602. (d) Wang, W.; Zhao, X.-M.; Wang, J.-L.; Geng, X.; Gong, J.-F.; Hao, X.-Q.; Song, M.-P. Tetrahedron Lett. 2014, 55, 3192.

(7) Reichardt, C. Solvents and Solvent Effects in Organic Chemistry; Wiley-VCH: Weinheim, 2003, 3rd ed.

(8) Mąkosza, M. Tetrahedron 1968, 24, 175.

(9) (a) Ji, P.; Atherton, J.; Page, M. I. Org. Biomol. Chem. 2012, 10, 5732. (b) Ji, P.; Atherton, J.; Page, M. I. J. Org. Chem. 2011, 76, 1425. (c) Ji, P.; Atherton, J.; Page, M. I. J. Org. Chem. 2011, 76, 3286.

(10) (a) van der Plas, H. C.; Woźniak, M. Croat. Chem. Acta 1968, 59, 33. (b) Szpakiewicz, B.; Grzegorek, M. Russ. J. Org. Chem. 2004, $40,829$.

(11) Mąkosza, M.; Staliński, K. Chem. Eur. J. 1997, 3, 2025.

(12) General Procedure for the Oxidation of Aldehydes to Amides in Liquid Ammonia

Under an argon atmosphere, liquid $\mathrm{NH}_{3}(25 \mathrm{~mL})$ was condensed in a two-neck round-bottom flask immersed in a dry ice cooling bath and equipped with a dry ice reflux condenser. Aldehyde 
(7.34 mmol) was added, and the resulting solution (or suspension) was stirred for $1 \mathrm{~h} . \mathrm{KMnO}_{4}(7.34 \mathrm{mmol}, 1.16 \mathrm{~g}$ ) was added, the cooling bath was removed, and the reaction mixture was stirred for another hour with gentle reflux of $\mathrm{NH}_{3} \cdot \mathrm{Na}_{2} \mathrm{SO}_{3}(22.0$ $\mathrm{mmol}, 2.78 \mathrm{~g}$ ) was added, the reflux condenser was removed, and the $\mathrm{NH}_{3}$ was allowed to evaporate spontaneously. The darkbrown residue was treated with $6 \mathrm{M} \mathrm{HCl}(30 \mathrm{~mL})$, and the resulting precipitate was filtered, washed with $\mathrm{H}_{2} \mathrm{O}(100 \mathrm{~mL})$ and sat. aq $\mathrm{NaHCO}_{3}(20 \mathrm{~mL})$. All products were recrystallized from EtOH.

\section{3-Bromobenzamide}

Colorless crystals; mp $152-156{ }^{\circ} \mathrm{C}$ (lit. $\left.{ }^{6 d} 157-159{ }^{\circ} \mathrm{C}\right)$. IR (KBr): $\mathrm{v}_{\max }=3353,3175,1659,1623,1564,1427,1389,1123,1066$, 901, $794 \mathrm{~cm}^{-1} .{ }^{1} \mathrm{H}$ NMR $(400 \mathrm{MHz}): \delta=7.44(1 \mathrm{H}, \mathrm{t}, J=7.8 \mathrm{~Hz})$, $7.56(1 \mathrm{H}, \mathrm{br} \mathrm{s}), 7.73(1 \mathrm{H}, \mathrm{ddd}, J=7.8,2.0,1.0 \mathrm{~Hz}), 7.90(1 \mathrm{H}, \mathrm{dm}$, $J=7.8 \mathrm{~Hz}), 8.08(1 \mathrm{H}, \mathrm{t}, J=1.8 \mathrm{~Hz}), 8.15(1 \mathrm{H}, \mathrm{br} \mathrm{s}) .{ }^{13} \mathrm{C}$ NMR $(100$ $\mathrm{MHz}): \delta=122.5,127.5,131.1,131.4,134.9,137.4,167.3$.

(13) Wiberg, K. B.; Steward, R. J. Am. Chem. Soc. 1955, 77, 1786.

(14) Mąkosza, M.; Staliński, K. Tetrahedron Lett. 1998, 39, 3575. 